\title{
Recommended standards for newborn ICU design
}

\author{
RD White, Consensus Committee Chairman \\ Regional Newborn Program, Memorial Hospital, South Bend, IN, USA
}

This paper presents the work of the sixth Consensus Committee on Recommended Standards for Newborn intensive care unit (NICU) design. Recommended standards for NICU structure, lighting, noise control, infection control, family support and other design considerations are offered, along with supporting interpretations, references and a glossary of terms. Journal of Perinatology (2006) 26, S2-S18. doi:10.1038/sj.jp.7211587

Keywords: NICU design; family-centered care; developmental care; access to nature; sustainable design

\section{Preface}

The recommended standards for newborn intensive care unit (NICU) design that follow are the result of an ongoing effort by many people. The participants in the 6th consensus conference who developed these standards are listed in the pages that follow, but we wanted to also recognize our International Advisory Committee who provided input during the consensus process, including Ken Appleman, Anne Augustin, Carlo Bellieni, Michael Dunn, Linda Franck, Maureen Gilmore, Carl Kuschel, Jerry King, Diane Paul, Neil Roy, Kaye Spence, Jane Sweeney and Lynne
Wilson-Orr. We also wish to acknowledge the professional advice of Jack Evans, Brian Kubicki and Edward Logsdon on Standard 23, and to thank Christa Plott for her technical support in preparing this document.

These standards have now been disseminated to more than 25 countries and several hundred NICUs, architectural firms, state planning agencies and medical professionals. Because upgrading these standards is a continuing process, we are anxious to get your feedback regarding any changes or additions you think are important for these standards so that we can incorporate these into our discussions. In addition, we would like to know the impact these standards are having on neonatal unit design and care. Please contact us to let us know how you are using these standards.

\section{Endorsements}

The following organizations have reviewed and endorsed the recommendations published in this report:

Council of International Neonatal Nurses, Edmund, OK, USA

Institute for Family-Centered Care, Bethesda, MD, USA

American Dietetic Association, Chicago, IL, USA

\section{Participants}

Joy Browne, PhD

Associate Professor

Department of Pediatrics at the Children's Hospital

University of Colorado

School of Medicine

1056 E19th Avenue

Denver, C0 80218

Tel: +13038616546

Fax: +1 3037648092

E-mail: browne.joy@tchden.org

Stanley $\mathbf{N}$ Graven, MD

Professor of Pediatrics

University of South Florida

13201 Bruce B. Downs Blvd.

Tampa, FL 33612-3805

\section{Robert Cicco, MD}

Pediatric Neonatal Associates

2015 Swallow Hill Road

Pittsburgh, PA 15220-1626

Tel: +1 4125785858

Fax: +1 4125781529

E-mail: tririver@comcast.net

Skip Gregory, NCARB

Bureau Chief

Agency for Health Care Administration

2727 Mahan Drive

Building \#1

\author{
Douglas Erickson \\ Consultant \\ American Society for Healthcare Engineering \\ P0 Box 1074 RS \\ St Croix \\ Virgin Islands 00821 \\ Tel: +1 8473470627 \\ Fax: +1 3407131771 \\ E-mail: derick@bigplanet.com
}

James W. Harrell, FAIA, FACHA

Director Healthcare Planning \& Design GBBN Architects Inc.

332 East 8th Street

Cincinnati, OH 45202

Correspondence: Dr RD White, Regional Newborn Program, Memorial Hospital, 615 N.

Michigan Street, South Bend, IN 46601, USA.

E-mail: robert_white@pediatrix.com 
Tel: +1 8139746694

Fax: +1 8139745172

E-mail: sgraven@health.usf.edu

Carol B Jaeger, MS, PNP, CNNP, RNC

Vice President

Clinical Services-Neonatal

Children Hospital

700 Children's Drive

Columbus, OH 43204-2696

Tel: +1 6147226216

Fax: +1 6147224768

E-mail: jaegerC@chi.osu.edu

\section{Kathleen JS Kolberg, PhD}

Health Sciences Office

Office of the Dean of Science

Jordan Hall of Science

University of Notre Dame

Notre Dame, IN 46556

Tel: +1 5746312846

Fax: +1 5746318883

E-mail: kkolberg@nd.edu

Carol A McGlone, RN, CIC

Epidemiology Nurse Specialist

Department of Epidemiology

Children's Hospital

700 Children's Drive

Columbus, OH 43205-2696

Tel: +1 6147224992

Fax: +1 6147226337

E-mail:mcglonec@chi.osu.edu

\section{Mark S Rea, PhD}

Professor and Director

Lighting Research Center

Rensselaer Polytechnic Institute

21 Union St

Troy, NY 12180

Tel: +1 5186877100

Fax: +1 5186877120

E-mail: ream@rpi.edu

\section{Walt Vernon, PEJD}

President

Mazzetti \& Associates Consultants \& Engineers

530 Bush Street

Suit 300

San Francisco, CA 94108

Tel: +1 4153623266

Fax: +1 4153623267

E-mail: walterv@mazzetti.com
Suite 145

Tallahassee, FL 32308

Tel: +1 8509226469

Fax: +1 8509226483

E-mail: gregorys@ahca.myflorida.com

Beverly H Johnson, President/CEO

Institute for Family-Centered Care

7900 Wisconsin Avenue,

Suite 405

Bethesda, MD 20814

Tel: +1 3016520281

Fax: +1 3016520186

E-mails: http://www.familycenteredcare.org/

bhjmom@earthlink.net

George A Little, MD

Professor of Pediatrics \& OB/GYN

Dartmouth-Hitchoock Medical Center

Lebanon, NH 03756

Tel: +1 6036505828

Fax: +1 6036505458

E-mail: george.a.little@dartmouth.edu

\section{Gilbert L Martin, MD}

Director, NICU

Pediatrix Medical Group

Citrus Valley Medical Center

1135 S. Sunset,

Suite 406

West Covina, CA 91719

Tel: +1 626-813-3716

Fax: +1 626-813-3720

E-mail: gilmartin@pol.net

\section{Mardelle McCuskey Shepley}

Director

Center for Health Systems \& Design

Interim Head

Department of Architecture

Texas A\&M University

College Station, TX 77843-3137

Tel: +1 9798457877

Fax: +1 9798621571

E-mail: mshepley@archmail.tamu.edu

\section{Robert D White, MD, Chairman}

Director

Regional Newborn Program

Memorial Hospital

615 N. Michigan Street

South Bend, IN 46601

Tel: +1 5746477351

Fax: +1 5746477248

E-mail: robert_white@pediatrix.com
Tel: +1 5132418700

Fax: +1 5132418873

E-mail: jharrell@gbbn.com

Carole Kenner, RNC, DNS, FAAN

Dean/Professor

University of Oklahoma Health Sciences

Center

College of Nursing

1100 North Stonewall Avenue

Oklahoma City, OK 73117

Tel: +1 4052712420

Fax: +1 4052713443

E-mail: carole-kenner@ouhsc.edu

Anna Marshall-Baker, PhD

Interior Architecture

University of North Carolina

259 Stone Building

Greensboro, NC 27402-6170

Tel: +1 3362560307

Fax: +1 3363345049

E-mail: anna marshallbaker@uncg.edu

M Kathleen Philbin, RN, PhD

Coordinator, Nursing Research

The Children's Hospital of Philadelphia 34th Street and Civic Center Blvd. Philadelphia, PA 19104-1000 Tel: +1 8569636708

Fax: +1 8563428007

E-mail: philbin@email.chop.edu

Judith A Smith, MHA

Principal

Smith Hager Bajo

19779 Spyglass Hill Court

Ashburn, VA 20147

Tel: +1 7037269770

Fax: +1 7037269771

E-mail: jsmith@shbajo.com 
S4

\section{Contents}

Introduction

Application of these standards

Substantive changes to 6th edition

The NICU

Standards:

1

Unit configuration NICU location within the hospital Minimum space, clearance and privacy requirements for the infant space Electrical, gas supply and mechanical needs Airborne infection isolation room(s) Family entry and reception area Handwashing stations General support space Staff support space Family transition room(s) Family support space

Support space for ancillary services Administrative space Ambient lighting in infant-care area Procedure lighting in infant-care areas Illumination of support areas Daylighting Floor surfaces Wall surfaces Furnishings Ceiling finishes Ambient temperature and ventilation Acoustic environment Safety/infant security Access to nature and other positive distractions

Glossary

References 


\section{Introduction}

The creation of formal planning guidelines for newborn intensive care units (NICUs) first occurred when Toward Improving the Outcome of Pregnancy was published in 1976. ${ }^{1}$ This landmark publication, written by a multidisciplinary committee and published by the March of Dimes, provided a rationale for planning and policy for regionalized perinatal care, as well as details of roles and facility design. Since then, the American Academy of Pediatrics (AAP) and American College of Obstetricians and Gynecologists (ACOG) have published several editions of their comprehensive Guidelines for Perinatal Care, ${ }^{2}$ and The American Institute of Architects has likewise published several editions of their Guidelines for Construction of Hospital and Healthcare Facilities. ${ }^{3}$ In 1993, Toward Improving the Outcome of Pregnancy was revised. ${ }^{4}$ The second TIOP reviewed medical and societal changes since the original document and formulated new recommendations in recognition of these developments, particularly the ascendance of managed care.

The purpose of this committee is to complement the above documents by providing health-care professionals, architects, interior designers, state health-care facility regulators and others involved in the planning of NICUs with a comprehensive set of standards based on clinical experience and an evolving scientific database.

With the support of Ross Products Division/Abbott Laboratories, a multidisciplinary team of physicians, nurses, state health planning officials, consultants and architects reached consensus on the first edition of these recommendations in January 1992. The document was then sent to all members of the AAP section on perinatal pediatrics to solicit their comments, and we also sought input from participants at the 1993 Parent Care Conference and at an open, multidisciplinary conference on NICU design held in Orlando in 1993. Subsequent editions of these recommended standards were then developed by consensus committees in 1993 , 1996, 1999 and 2002, under the auspices of the Physical and Developmental Environment of the High-Risk Infant Project.

Various portions of these recommended standards have now been adopted by the American Institute of Architects' Guidelines, ${ }^{3}$ the AAP/ACOG Guidelines ${ }^{2}$ and by standards documents in several other countries. In the future, we will continue to update these recommendations on a regular basis, incorporating new research findings, experiences and suggestions.

It is our hope that this document will continue to provide the basis for a consistent set of standards that can be used by all states and endorsed by appropriate national organizations, and that it will also continue to be useful in the international arena.

Although many of these standards are minimums, the intent is to optimize design within the constraints of available resources, and to facilitate excellent healthcare for the infant in a setting that supports the central role of the family and the needs of the staff.
Decision makers may find these standards do not go far enough, and resources may be available to push further towards the ideal.

\section{Application of these standards}

Unless specified otherwise, the following recommendations apply to the newborn intensive care built environment, although most have broader application for the care of ill infants and their families.

Where the word shall is used, it is the consensus of the committee participants that the standard is appropriate for future NICU constructions. We recognize that it may not be reasonable to apply these standards to existing NICUs or those undergoing limited renovation.

We also recognize the need to avoid statements requiring mandatory compliance, unless a clear scientific basis or consensus exists. The standards presented in this document address only those areas where we believe such data or consensus are available.

Individuals and organizations applying these standards should understand that this document is not meant to be all encompassing. It is intended to provide guidance for the planning team to apply the functional aspects of operations with sensitivity to the needs of infants, family and staff. The program planning and design process should include research, evidence-based recommendations and materials, with objective input of experts in the field in addition to the internal interdisciplinary team. The design should creatively reflect the vision and spirit of the infants, families and staff of the unit. The program and design process should include:

Review of articles on practice, teambuilding and planning Education in the change process

Visits to new and renovated units

vendor fairs

Vision and goals

Program planning

Space planning, including methods to visualize 3-D space Operations planning, including traffic patterns, functional locations and relationship to ancillary services

Interior planning

Surface materials selection

Review of blueprints, specifications, other documents and mock-ups

Building and construction

Post-construction verification and remediation.

\section{Substantive changes - 6th edition}

In the four short years since the last edition of these recommended standards, remarkable changes have occurred in the 'landscape' of NICU design. Private or single-family room designs, formerly a rarity, are now so common as to be the primary feature of most 
new construction projects in the US, driven by a dramatic increase in evidence that such designs are practical, popular with families, and justified by an increasing awareness of the impact of the sensory environment on premature and ill newborns. Much of this evidence is cited in an issue of Clinics in Perinatology to which many members of the consensus committee contributed. ${ }^{5}$ Secondly, electronic medical records and wireless communication devices have become much more prevalent. Finally, the impetus for sustainable design has strengthened, and is now viewed as both practical and imperative. These changes and more are reflected in this new edition of the recommended standards; we summarize the most substantive changes below.

Standard 12: support space for ancillary services. We added language in the interpretation section that identified a specialized feedings preparation area as a space that should be provided in the NICU unless this function is performed elsewhere in the hospital, and specified certain features that should be included.

Standard 14: ambient lighting in infant-care areas. We further described criteria for appropriate ambient light quality; in addition to a color-rendering index (CRI) of 80 or greater, we also specified that this lighting must have a full-spectrum color index (FSCI) of 55 or greater, and a gamut area (GA) of no less than 65 and no more than 100 .

\section{Standard 16: illumination of support areas}

We added a recommendation to consider addition of an area where staff can receive exposure to high-intensity light for at least $15 \mathrm{~min}$ to ameliorate the effects of night-shift work and seasonal affective disorder.

Standard 18: floor surfaces. High-gloss flooring is prohibited. Flooring is required to be free of toxins, selected from regional sources when possible, and installed early enough to allow at least 2 weeks for off gassing before occupancy. Some of these requirements also appear in the standards on other finishes in the NICU, including walls, ceilings and casework.

Standard 21: ceiling finishes. The noise reduction coefficient (NRC) requirement has been increased from 0.9 to 0.95 .

Standard 23: acoustical environment. The acceptable maximum sound levels have been reduced to an $L_{\text {eq }}$ of $45, L_{10}$ of 50 and $L_{\max }$ of 65 . To support this requirement, the noise criterion for heating, ventilation and air conditioning (HVAC) and other mechanical equipment has been established as no greater than 35 , and extensive supportive language in the interpretation provides assistance to planning teams so that this requirement can be met.
New standard (25): access to nature and other positive distractions. A new standard has been written that requires opportunities for access to nature (broadly defined) for both staff and families.

In several standards related to materials used (flooring, ceiling finishes, etc.), we have specified that these be free of toxic substances to the greatest extent possible, as well as recycled/ recyclable, and obtained from regional sources whenever possible.

We made several other less substantive changes in the recommended standards which are not summarized here as they are not likely to have a significant impact on the design process, but were part of our effort to be sure that the standards are as useful and contemporary as possible.

\section{The NICU}

No consensus national standard of what constitutes an NICU exists. Some states have defined levels of care, whereas other states have informal or no systems for classification. The AAP has defined NICU levels of care based primarily on availability of specialized equipment and staff ${ }^{2}$, but such units often encompass both intensive and step-down or intermediate care.

For the purposes of this document, newborn intensive care is defined as care for medically unstable or critically ill newborns requiring constant nursing, complicated surgical procedures, continual respiratory support or other intensive interventions.

Intermediate care includes care of ill infants requiring less constant nursing, but does not exclude respiratory support. When an intensive care nursery is available, the intermediate nursery serves as a 'step down' unit from the intensive care area. When hospitals mix infants of varying acuity, requiring different levels of care in the same area, intensive care design standards shall be followed to provide maximum clinical flexibility.

\section{Standards}

\section{Standard 1: unit configuration}

The NICU design shall be driven by systematically developed program goals and objectives that define the purpose of the unit, service provision, space utilization, projected bed space demand, staffing requirements and other basic information related to the mission of the unit. Design strategies to achieve program goals and objectives shall address the medical, developmental, educational, emotional and social needs of infants, families and staff. The design shall allow for flexibility and creativity to achieve the stated objectives.

The NICU shall be configured to individualize the care giving environment and services for each infant and family.

Interpretation. Program goals and objectives congruent with the philosophy of care and the unit's definition of quality should be 
developed by a planning team. This team should include, among others, health-care professionals, families (whose primary experience with the hospital is as consumers of health care), administrators and design professionals.

The program goals and objectives should include a description of those services necessary for the complete operation of the unit and address the potential need to expand services to accommodate increased demand.

The specific approaches to achieve individualized environments are addressed in subsequent sections.

\section{Standard 2: NICU location within the hospital}

The NICU shall be a distinct area within the health-care facility, with controlled access and a controlled environment.

The NICU shall be located within space designed for that purpose. It shall provide effective circulation of staff, family and equipment. Traffic to other services shall not pass through the unit.

The NICU shall be in close and controlled proximity to the area of the hospital where births occur. When obstetric and neonatal services must be on separate floors of the Hospital, an elevator located adjacent to the units with priority call and controlled access by keyed operation shall be provided for service between the birthing unit and the NICU.

Units receiving infants from other facilities shall have ready access to the hospital's transport-receiving area.

Interpretation. The purpose of this standard is to provide safe and efficient transport of infants while respecting their privacy. Accordingly, the NICU should be a distinct, controlled area immediately adjacent to other perinatal services, except in those local situations (e.g., free-standing children's hospitals) where exceptions can be justified. Transport of infants within the hospital should be possible without using public corridors.

\section{Standard 3: minimum space, clearance and privacy requirements for the infant space}

Each infant space shall contain a minimum of $120 \mathrm{ft}^{2}\left(11.2 \mathrm{~m}^{2}\right)$ of clear floor space, excluding handwashing stations, columns and aisles (see Glossary). There shall be an aisle adjacent to each infant space with a minimum width of $4 \mathrm{ft}(1.2 \mathrm{~m})$ in multiple bedrooms. When single-infant rooms or fixed cubicle partitions are utilized in the design, there shall be an adjacent aisle of not less than $8 \mathrm{ft}(2.4 \mathrm{~m})$ in clear and unobstructed width to permit passage of equipment and personnel.

In multiple bedrooms, there shall be a minimum of $8 \mathrm{ft}(2.4 \mathrm{~m})$ between infant beds. Each infant space shall be designed to allow privacy for the infant and family.

Interpretation. These numbers are minimums and often need to be increased to reflect the complexity of care rendered, bedside space needed for parenting and family involvement in care, and privacy for families.

Infant space for intensive care infant beds situated in a singleinfant room should be at least 150 net square feet $\left(14 \mathrm{~m}^{2}\right)$ per infant to provide adequate space for equipment and families. The width of aisles in multiple bedrooms should allow for easy movement of all equipment that might be brought to the infant's bedside, as well as easy access for a maternal bed. The width of the corridors or aisles outside single-infant rooms or infant spaces designed with permanent cubicle partitions should allow for simultaneous passage of two such items as mandated by state and federal architectural and fire codes.

The need for privacy for infants and families should be addressed not only in design of each bed space, but also in the overall unit design - for example, by minimizing traffic flow past each bed.

\section{Standard 4: electrical, gas supply and mechanical needs}

Mechanical requirements at each infant bed, such as electrical and gas outlets, shall be organized to ensure safety, easy access and maintenance.

There shall be a minimum of 20 simultaneously accessible electrical outlets. The minimum number of simultaneously accessible gas outlets is:

Air 3 ,

Oxygen 3 and

Vacuum 3 .

There shall be a mixture of emergency and normal power for all electrical outlets per current National Fire Protection Association recommendations. ${ }^{6}$

There shall be provision at each bedside to allow data transmission to a remote location.

Interpretation. A system that includes easily accessible raceways for electrical conduit and gas piping, workspace and equipment placement is recommended because it permits flexibility to modify or upgrade mechanical features. All outlets should be positioned to maximize access and flexibility. Standard duplex electrical outlets may not be suitable, as each outlet may not be simultaneously accessible for oversized equipment plugs. The number of electrical, gas and suction outlets specified is a minimum; access to more may be necessary for critically ill infants. This area should also include communication devices, supply storage and charting space, resulting in an efficient, organized and self-contained workstation around the infant.

\section{Standard 5: airborne infection isolation room(s)}

An airborne infection isolation room shall be available for NICU infants. A hands-free handwashing station for hand hygiene and areas for gowning and storage of clean and soiled materials shall be provided near the entrance to the room. Ventilation systems for 
isolation rooms shall be engineered to have negative air pressure with air $100 \%$ exhausted to the outside. Airborne infection isolation room perimeter walls, ceilings and floors, including penetrations, shall be sealed tightly so that air does not infiltrate the environment from the outside or from other airspaces.

Airborne infection isolation rooms shall have self-closing devices on all room exit doors. An emergency communication system and remote patient monitoring capability shall be provided within the airborne infection isolation room.

Airborne infection isolation rooms shall have observation windows with internal blinds or switchable privacy (opaquing) glass for privacy. Placement of windows and other structural items shall allow for ease of operation and cleaning.

Airborne infection isolation rooms shall have a permanently installed visual mechanism to constantly monitor the pressure status of the room when occupied by a patient with an airborne infectious disease. The mechanism shall continuously monitor the direction of the airflow.

Interpretation. An airborne infection isolation room adequately designed to care for ill newborns should be available in any hospital with an NICU. In most cases, this is ideally situated within the NICU, but in some circumstances, utilization of an airborne infection isolation room elsewhere in the hospital (e.g., in a pediatric intensive care unit) would be suitable.

Airborne infection isolation rooms should have a minimum of $150 \mathrm{ft}^{2}$ of clear floor space, excluding the entry work area.

At least one single-occupancy isolation room should be available for any infant with a suspected airborne infection. A space within the NICU should also be available to safely cohort a group of infants infected with or exposed to a common airborne pathogen.

When not used for isolation, these rooms may be used for care of non-infectious infants and other clinical purposes.

\section{Standard 6: family entry and reception area}

The NICU shall have a clearly identified entrance and reception area for families. Families shall have immediate and direct contact with staff when they arrive at this entrance and reception area.

Interpretation. The design of this area should contribute to positive first impressions for families and foster the concept that families are important members of their infant's health-care team, not visitors. Facilitating contact with staff will also enhance security for infants in the NICU.

This area should have lockable storage facilities for families' personal belongings (unless provided elsewhere), and may also include a handwashing and gowning area.

\section{Standard 7: bandwashing stations}

Where a single-infant room concept is used, a hands-free handwashing station shall be provided within each infant room. In a multiple bedroom, every infant bed shall be within $20 \mathrm{ft}(6 \mathrm{~m})$ of a hands-free handwashing station. Handwashing stations shall be no closer than $3 \mathrm{ft}(0.9 \mathrm{~m})$ from an infant bed or clean supply storage.

Handwashing sinks shall be large enough to control splashing and designed to avoid standing or retained water. Minimum dimensions for a handwashing sink are 24 inches wide $\times 16$ inches front to back $\times 10$ inches deep $(61 \mathrm{~cm} \times 41 \mathrm{~cm} \times 25 \mathrm{~cm})$ from the bottom of the sink to the top of its rim. Space for pictorial handwashing instructions shall be provided above all sinks. There shall be no aerator on the faucet. Walls adjacent to handwashing sinks shall be constructed of non-porous material. Space shall also be provided for soap and towel dispensers and for appropriate trash receptacles. Towel dispensers shall operate so that only the towel itself need be touched in the process of dispensing, and constructed in such a manner as to be consistent with Standard 23.

Handwashing facilities located at a level where they can be used by people in wheelchairs shall be available in the NICU.

Separate receptacles for biohazardous and non-biohazardous waste shall be available.

Interpretation. Sinks for handwashing should not be built into counters. Sink location, construction material and related hardware (paper towel and soap dispensers) should be chosen with durability, ease of operation, ease of cleaning and noise control in mind. Non-absorbent wall material should be used around sinks to prevent the growth of mold on cellulose material.

Local, state and federal regulatory agencies dictate what healthcare-generated waste is biohazardous or non-biohazardous and appropriate disposal methods that are dependent on the type of waste. Depending upon the jurisdiction, biohazard signage may need to be affixed.

\section{Standard 8: general support space}

Distinct facilities shall be provided for clean and soiled utilities, medical equipment storage and unit management services.

Clean utility/bolding area(s): For storage of supplies frequently used in the care of newborns.

Soiled utility/holding room: Essential for storing used and contaminated material before its removal from the care area. Unless used only as a holding room, this room shall contain a counter and a hands-free handwashing station separate from any utility sinks. The handwashing station shall have hot and cold running water that is turned on and off by hands-free controls, soap and paper towel dispensers, and a covered waste receptacle with foot control.

The ventilation system in the soiled utility/holding room shall be engineered to have negative air pressure with air $100 \%$ 
exhausted to the outside. The soiled utility/holding room shall be situated to allow removal of soiled materials without passing through the infant-care area.

A designated area for collection of recyclable materials used in the NICU shall be established. ${ }^{7}$ This area shall measure at least $1 \mathrm{ft}^{2}$ per patient bed and be located outside the patient-care area.

Charting/staff work areas: Provision for charting space at each bedside shall be provided. An additional separate area or desk for tasks such as compiling more detailed records, completing requisitions and telephone communication shall be provided in an area acoustically separated from the infant and family areas. Dedicated space shall be allocated as necessary for electronic medical record keeping within infant-care areas.

Interpretation. Storage areas: A three-zone storage system is desirable. The first storage area should be the central supply department of the hospital.

The second storage zone is the clean utility area described in the standard; it should be adjacent to and acoustically separated from the infant-care area. Routinely used supplies such as diapers, formula, linen, cover gowns, charts and information booklets may be stored in this space. There should be at least $8 \mathrm{ft}^{3}\left(0.22 \mathrm{~m}^{3}\right)$ for each infant for secondary storage of syringes, needles, intravenous infusion sets and sterile trays.

There should also be at least $18 \mathrm{ft}^{2}\left(1.7 \mathrm{~m}^{2}\right)$ of floor space allocated for equipment storage per infant in intermediate care, and $30 \mathrm{ft}^{2}\left(2.8 \mathrm{~m}^{2}\right)$ for each infant bed in intensive care. Total storage space may vary by unit size and storage system.

Easily accessible electrical outlets are desirable in this area for recharging equipment.

The third storage zone is for items frequently used at the infant's bedside. Bedside cabinet storage should be at least $16 \mathrm{ft}^{3}$ $\left(0.45 \mathrm{~m}^{3}\right)$ for each infant in the intermediate care area and $24 \mathrm{ft}^{3}$ $\left(0.67 \mathrm{~m}^{3}\right)$ for each infant in the intensive care area. Bedside storage should be designed for quiet operation.

Hospitals contribute significant waste each year to incinerators and landfills. This creates not only an environmental hazard, but also conditions that are harmful to human health. Providing a designated collection area enables staff to separate and store for collection waste such as paper, newsprint, corrugated cardboard, plastics, metals, batteries, fluorescent lamps and glass to either facilitate existing hospital procedures for recycling or initiate a recycling system. Space within the designated collection area may also be used for collection of medical supplies for distribution to hospitals or clinics in need of such materials.

Charting/staff work areas: A clerical area should be located near the entrance to the NICU so that personnel can supervise traffic into the unit. In addition, there should be one or more staff work areas, each serving 8 to 16 beds. These areas will allow groups of 3 to 6 caregivers to congregate immediately adjacent to the infant-care area for report, collaboration and socialization without impinging on infant or family privacy. Infants' charts, computer terminals and hospital forms may be located in this space.

Design of the NICU must anticipate use of electronic medical record devices so that their introduction does not require major disruption of the function of the unit or impinge on space designed for other purposes. Design considerations include ease of access for staff, patient confidentiality, infection control and noise control, both with respect to that generated by the devices and by the traffic around them.

Laundry room: If laundry facilities for infant materials are provided, a separate laundry room can serve the functions of laundry and toy cleaning within the NICU. Infant clothing and the cloth covers of positioning aids should be laundered on a regular schedule and as needed. In addition, toys utilized by infants or siblings are required to be cleaned on a regular schedule for each infant and between infants. Space for a commercial-grade washer and dryer should be accommodated. The dryer should be vented through an outside wall. The placement of a commercial-grade dishwasher could promote the efficiency and effectiveness of the aseptic cleaning process for toys.

\section{Standard 9: staff support space}

Space shall be provided within the NICU to meet the professional, personal and administrative needs of the staff. Rooms shall be sized and located to provide privacy and to satisfy their intended function. Locker, lounge, private toilet facilities and on-call rooms are required at a minimum.

Interpretation. Support elements can be defined as those that facilitate the provision of infant care and the well being of the staff; they may account for at least one-third of the floor space of the entire unit.

Staffing areas are defined as space limited to use by staff members to meet personal, professional and administrative needs. These areas include lockers, lounges, counseling, education and conference space, and on-call rooms that provide privacy and satisfy their intended function.

\section{Standard 10: family transition room(s)}

Family-infant room(s) shall be provided within or immediately adjacent to the NICU that allow(s) families and infants extended private time together.

The room(s) shall have direct, private access to sink and toilet facilities, emergency call and telephone or intercom linkage with the NICU staff, sleeping facilities for at least one parent, and sufficient space for the infant's bed and equipment.

The room(s) can be used for other family support, educational, counseling or demonstration purposes when unoccupied. 
Interpretation. Access to family-infant room(s) encourages overnight stays by parents and the infant in the NICU. The room(s) should be sufficiently equipped and sized to accommodate the parents, with additional space for a physician, nurse, social worker, chaplain or other individuals who may need to meet with the parents and baby in private.

For security reasons, transition room(s) should be situated within an area of controlled public access.

The number of electrical, medical gas and suction outlets specified will be dependent on the function(s) intended for this area.

Sufficient family-infant rooms should be provided to allow those families who wish to room in with their infants the opportunity to do so. The appropriate number of rooms will depend on each hospital's practice pattern, the number of single-infant rooms with parent sleeping facilities, the availability of other rooms nearby, the size of the region served and other variables.

\section{Standard 11: family support space}

Space shall be provided in or immediately adjacent to the NICU for the following functions: family lounge area, lockable storage, telephone(s) and toilet facilities. Separate, dedicated rooms shall also be provided for lactation support and consultation in or immediately adjacent to the NICU. A family library or education area shall be provided within the hospital. Access to the internet and educational materials shall be provided via a computer station in the family lounge or at the infant's bedside.

Interpretation. Family lounge area: This should include comfortable and moveable seating, as well as a play area stocked with entertainment materials for children. A nourishment area should also be considered, as well as external windows or skylights.

Lockable storage: Secure storage for personal items should be provided at each infant space.

Lactation support: Comfortable seating, a handwashing sink and a means of communication to the NICU should be provided.

Family education area: This should include publications, audiovisual resources and internet access so that families can learn about health conditions, child development, parenting issues and parent-to-parent support. This area might also include space and supplies to learn about and practice caregiving techniques.

Telephones: Telephones should be provided that offer privacy and that enable an individual to sit down while talking.

Consultation room: This should include comfortable seating and allow complete visual and acoustic privacy.

\section{Standard 12: support space for ancillary services}

Distinct support space shall be provided for all clinical services that are routinely performed in the NICU.
Interpretation. Ancillary services such as (but not necessarily limited to) respiratory therapy, laboratory, pharmacy, radiology, developmental therapy and specialized feeding preparation are common in the NICU. Distance, size and access are important considerations when designing space for each of these functions. Satellite facilities may be required to provide these services in a timely manner.

Unless performed elsewhere in the hospital, a specialized feedings preparation area or room should be provided in the NICU, away from the bedside, to permit mixing of additives to breast milk or formula. This area should be equipped with a hands-free handwashing station, counter work space and storage areas for supplies, formula and both refrigerated and frozen breast milk. ${ }^{8}$

\section{Standard 13: administrative space}

Administrative space shall be provided in the NICU for activities directly related to infant-care, family support or other activities routinely performed within the NICU.

Interpretation. A wide range of personnel is assigned to the NICU, many of whom require office or administrative space. When planning the NICU, administrative space should be considered for each discipline that provides service to the unit on a daily basis and needs a distinct area for carrying out their responsibilities, even if that individual has additional office space elsewhere.

\section{Standard 14: ambient lighting in infant-care areas}

Ambient lighting levels in infant spaces shall be adjustable through a range of at least 10 to no more than 600 lux (approximately 1 to 60 foot candles), as measured at each bedside. Both natural and electric light sources shall have controls that allow immediate darkening of any bed position sufficient for transillumination when necessary.

Electric light sources shall have a CRI $^{9}$ of no less than 80 , a FSCI10 of no less than 55 , and a $\mathrm{GA}^{10}$ of no less than 65 and no greater than 100 . The sources shall avoid unnecessary ultraviolet or infrared radiation by the use of appropriate lamps, lens or filters. ${ }^{11}$

No direct view of the electric light source or sun shall be permitted in the infant space (as described in Standard 3): this does not exclude direct procedure lighting, as described in Standard 15. Any lighting used outside the infant-care area shall be located so as to avoid any infant's direct line of sight to the fixture.

Lighting fixtures shall be easily cleaned.

Interpretation. Substantial flexibility in lighting levels is required by this standard so that the disparate needs of infants at various stages of development and at various times of day can be accommodated, as well as the needs of caregivers. In very preterm infants, there has been no demonstrable benefit to exposure to light. After 28 weeks gestation, there is some evidence that diurnally 
cycled lighting has potential benefit to the infant. ${ }^{12}$ Caregivers benefit from moderate levels of ambient light in order to perform tasks and maintain wakefulness.

Control of illumination should be accessible to staff and families, and capable of adjustment across the recommended range of lighting levels. Use of multiple light switches to allow different levels of illumination is one method helpful in this regard, but can pose serious difficulties when rapid darkening of the room is required to permit transillumination, so a master switch should also be provided.

Perception of skin tones is critical in the NICU; light sources that meet the CRI, FSCI and GA values identified above provide accurate skin-tone recognition. Light sources should be as free as possible of glare or veiling reflections. When the light sources to be used are linear fluorescent lamps, these color criteria can be met by using lamps that carry the color designation 'RE80'.

\section{Standard 15: procedure lighting in infant care areas}

Separate procedure lighting shall be available to each infant bed. The luminaire shall be capable of providing no less than 2000 lux at the plane of the infant bed, and must be framed so that no more than $2 \%$ of the light output of the luminaire extends beyond its illumination field. This lighting shall be adjustable so that lighting at less than maximal levels can be provided whenever possible.

Interpretation. Temporary increases in illumination necessary to evaluate a baby or to perform a procedure should be possible without increasing lighting levels for other babies in the same room.

As intense light may be unpleasant and harmful to the developing retina, every effort should be made to prevent direct light from reaching the infant's eyes. Procedure lights with adjustable intensity, field size and direction will help protect the infant's eyes from direct exposure and provide the best visual support to staff.

\section{Standard 16: illumination of support areas}

Illumination of support areas within the NICU, including the charting areas, medication preparation area, the reception desk and handwashing areas, shall conform to IESNA specifications. ${ }^{11}$

Interpretation. Illumination should be adequate in areas of the NICU where staff perform important or critical tasks; the IESNA specifications in these areas are similar to but somewhat more specific than the general guidelines recommended by AAP/ACOG. ${ }^{2}$

In locations where these functions overlap with infant-care areas (e.g., close proximity of the staff charting area to infant beds), the design should nevertheless permit separate light sources with independent controls so that the very different needs of sleeping infants and working staff can be accommodated to the greatest possible extent. Care must be taken, however, to insure that bright light from these locations does not reach the infants' eyes (see Standard 14).

Consideration should be given to providing a space easily accessible to all staff that will provide an opportunity for exposure to higher-intensity light levels for at least 15 min a shift in order to ameliorate the effects of working at night and seasonal affective disorder. ${ }^{13}$ This space can be illuminated with white light to produce 300 to 500 lux at the eye, which is produced by approximately 1500 to 2500 lux at the work plane. If a blue local lighting system is used, the illumination should be from a spectrally narrowband source - such as a blue LED - with a peak wavelength at or near $470 \mathrm{~nm}$, and should produce at least 30 lux at the eye. ${ }^{14}$

\section{Standard 17: daylighting}

At least one source of daylight shall be visible from infant-care areas, either from each infant room itself or from an adjacent staff work area. When provided, external windows in infant-care rooms shall be glazed with insulating glass to minimize heat gain or loss, and shall be situated at least $2 \mathrm{ft}(61 \mathrm{~cm})$ away from any part of an infant's bed to minimize radiant heat loss. All external windows shall be equipped with shading devices that are neutral color or opaque to minimize color distortion from transmitted light.

Interpretation. Windows provide an important psychological benefit to staff and families in the NICU. ${ }^{9,15}$ Properly designed daylighting is the most desirable illumination for nearly all caregiving tasks, including charting and evaluation of infant skin tone.

However, placing infants too close to external windows can cause serious problems with radiant heat loss or gain and glare, therefore provision of windows in the NICU requires careful planning and design.

Shading devices should be easily controlled to allow flexibility at various times of day, and should either be contained within the window or easily cleanable. These should be designed to avoid direct sunlight from striking the infant, IV fluids or monitor screens.

\section{Standard 18: floor surfaces}

Floor surfaces shall be easily cleanable and shall minimize the growth of microorganisms.

Flooring material with a reflectance of no greater than $40 \%{ }^{9}$ and a gloss value of no greater than 30 gloss units shall be used, ${ }^{16,17}$ to minimize the possibility that glare reflected from a bright procedure or work-area light will impinge on the eyes of infants or caregivers.

Floors shall be highly durable to withstand frequent cleaning and heavy traffic. 
S12

Flooring materials shall be free of substances known to be teratogenic, mutagenic, carcinogenic or otherwise harmful to human health.

Interpretation. Although ease of cleaning and durability of NICU surfaces are of primary importance, consideration should also be given to their glossiness (the mirror-like reflectivity of a surface), ${ }^{18}$ their acoustical properties and the density of the materials used. Reduced glossiness will reduce the risks from bright-reflected glare; acoustic and density properties will directly affect noise and comfort.

Materials should permit cleaning without the use of chemicals that may be hazardous, as it may not be possible to vacate the space during cleaning.

Transition surfaces that do not obstruct mobility, are durable, and minimize noise and jarring of equipment should be provided at the intersection of different flooring materials.

Materials suitable to these criteria include resilient sheet flooring (medical grade rubber or linoleum) and carpeting with an impermeable backing, heat- or chemically welded seams and antimicrobial and antistatic properties. Carpeting has been shown to be an acceptable floor covering in the hospital ${ }^{19}$ and the NICU $^{20}$ and has obvious aesthetic and noise reduction (NR) appeal, but it is not suitable in all areas (e.g., around sinks or in isolation or soiling utility/holding areas). Small floor tiles (e.g., 12 inch squares) have myriad seams and areas of non-adherence to the sub-floor. These harbor dirt and fluids are a potential source of bacterial and fungal growth.

Much is known ${ }^{21}$ regarding the effects of chemicals such as mercury on human health and development. Additional efforts should be made to exclude persistent, bioaccumulative toxic chemicals (PBTs) such as polyvinyl chloride (PVC) from healthcare environments. PVC or vinyl is common in flooring materials including sheet goods, tiles and carpet. The production of PVC generates dioxin, a potent carcinogen and fumes emitted from vinyl degrade indoor air quality. Dioxin releases are not associated with materials such as polyolefin, rubber (latex) or linoleum.

Volatile organic compounds (VOCs) such as formaldehyde and chlorinated compounds such as neoprene should also be avoided when selecting adhesives or sealants for floor coverings. Specify low- or no-VOC and non-toxic and non-carcinogenic materials. Flooring-containing natural rubber (latex) should be certified non-allergenic by the manufacturer.

Infants should not be moved into an area of newly installed flooring for a minimum of 2 weeks to permit complete off gassing of adhesives and flooring materials.

\section{Standard 19: wall surfaces}

Wall surfaces shall be easily cleanable and provide protection at points where contact with movable equipment is likely to occur.
Surfaces shall be free of substances known to be teratogenic, mutagenic, carcinogenic or otherwise harmful to human health.

Interpretation. As with floors, the ease of cleaning, durability and acoustical properties of wall surfaces must be considered. Although commonly used, vinyl wall covering contains PVC and will degrade indoor air quality, and thus should be avoided. VOCs and PBTs such as cadmium often are found in paints, wallcoverings, acoustical wall panels and wood paneling systems and also should be avoided. Specify low- or no-VOC paints and coatings.

\section{Standard 20: furnishings}

Built-in and freestanding furnishings such as cabinets and carts, especially those in the infant-care areas, shall be easily cleanable with the fewest possible seams in the integral construction. Exposed surface seams shall be sealed. Furnishings shall be of durable construction to withstand impact by movable equipment without significant damage.

Furnishings and materials shall be free of substances known to be teratogenic, mutagenic, carcinogenic or otherwise harmful to human health.

Interpretation. Countertops should have the fewest possible seams. Edges exposed to impact should be 'soft' (i.e., bull-nosed). Corners created at wall or backsplash intersections should be coved. Intersections with sinks or other devices should be sealed or made integral with the top. Casework construction should not chip or flake when struck by objects in the normal routine of infant care, and should be of sufficient moisture resistance to prevent deterioration.

Furnishings in the NICU are often composite pieces, made of various parts and layers of materials that are assembled with glue or adhesives. Materials and substances typically used in these furnishings often contain VOCs such as formaldehyde, which is frequently found in pressed wood products including plywood and particle board. Vinyl-based laminates, which often are applied to the surface of pressed wood products, also contain VOCs such as PVC. Specify low- or no-VOC materials, including ureaformaldehyde-free adhesives, for all furnishings in the NICU.

Specifying furnishings and materials from regional sources (within a 300 to 500 mile radius) not only provides support for the local community, but also reduces the amounts of fossil fuels necessary for transport.

\section{Standard 21: ceiling finishes}

Ceilings shall be easily cleanable and constructed in a manner to prohibit the passage of particles from the cavity above the ceiling plane into the clinical environment.

The ceiling construction shall not be friable and shall have a $\mathrm{NRC}^{22}$ of at least 0.95 . 
Finishes shall be free of substances known to be teratogenic, mutagenic, carcinogenic or otherwise harmful to human health.

Interpretation. As sound abatement is a high priority in the NICU, acoustical ceiling systems are desirable, but must be selected and designed carefully to meet this standard.

VOCs and PBTs such as cadmium are often found in paints and ceiling tiles and should be avoided. Specify low- or no-VOC paints and coatings.

\section{Standard 22: ambient temperature and ventilation}

The NICU shall be designed to provide an air temperature of 72 to $78^{\circ} \mathrm{F}\left(22\right.$ to $\left.26^{\circ} \mathrm{C}\right)$ and a relative humidity of 30 to $60 \%,{ }^{23}$ while avoiding condensation on wall and window surfaces.

A minimum of six air changes/hour is required, with a minimum of two changes being outside air.

The ventilation pattern shall inhibit particulate matter from moving freely in the space, and intake and exhaust vents shall be situated to minimize drafts on or near the infant beds. Ventilation air delivered to the NICU shall be filtered with at least the efficiency specified in the AIA Guidelines. ${ }^{3}$ Filters shall be located outside the infant-care area so that they can be changed easily and safely.

Fresh air intake shall be located at least $25 \mathrm{ft}(7.6 \mathrm{~m})$ from exhaust outlets of ventilating systems, combustion equipment stacks, medical/surgical vacuum systems, plumbing vents, or areas that may collect vehicular exhausts or other noxious fumes. Prevailing winds or proximity to other structures may require greater clearance.

Interpretation. Heat sources near the exterior wall, if applicable, should be considered to ameliorate the 'cold wall' condition, which in turn can be a source of convection drafts. This application of heat may also alleviate the conditions leading to condensation on these walls.

The airflow pattern should be at low velocity and designed to minimize drafts, noise levels and airborne particulate matter. A HEPA filtration system may provide improved infection control for immunocompromised patients.

Because a regular maintenance program is necessary to assure that systems continue to function as designed after occupancy, NICU design should attempt to maximize the ease of maintenance while minimizing its cost.

\section{Standard 23: acoustic environment}

Infant bed areas (including airborne infection isolation areas), staff work areas, family areas, and staff lounge and sleeping areas and the spaces opening onto them shall be designed to produce minimal background noise and to contain and absorb much of the transient noise that arises within them. The combination of continuous background sound and transient sound in any of these areas shall not exceed an hourly $L_{\mathrm{eq}}$ of $45 \mathrm{~dB}$ and an hourly $L_{10}$ of
$50 \mathrm{~dB}$, both A-weighted, slow response. Transient sounds or $L_{\max }$ shall not exceed $65 \mathrm{~dB}$, A-weighted, slow response.

To achieve these conditions, the noise criteria (NC) for the HVAC systems, other mechanical systems including plumbing, and equipment in each of these areas shall be a maximum of NC 35 . Ceiling surface materials in infant care, family and staff work areas and the areas opening onto them shall have a NRC of at least 0.95 (Standard 21). Announcing systems shall have adjustable volume controls for the speakers in each room and for each microphone that sends signal through the system. Doors and operable windows to infant-care areas, adult rest and sleep rooms, and staff work and break areas shall be designed to meet NC 35 requirements and shall have acoustic seals.

Interpretation. The acoustic environment is a function of both the facility (e.g., mechanical systems of the building, the intrusion of exterior sounds, the sound containment afforded by doors and walls and the sound absorption afforded by surface finishes) and operations (e.g., the activities of people and function of equipment and furnishings).

The acoustic conditions of the NICU should favor speech intelligibility, normal or relaxed vocal effort, acoustic privacy for staff and parents, and physiologic stability, uninterrupted sleep and freedom from acoustic distraction for infants and adults. ${ }^{24}$ Such favorable conditions encompass more than the absence of noise and require specific planning for their achievement. Speech intelligibility ratings in infant areas, parent areas and staff work areas should be 'good' to 'excellent' as defined by the International Organization for Standardization ISO 9921:2003. Speech

intelligibility for non-native but fluent speakers and listeners of a second language requires a 4 to $5 \mathrm{~dB}$ improvement in signal-tonoise ratio for similar intelligibility with native speakers. The $L_{\mathrm{eq}}$, $L_{10}$ and $L_{\max }$ limits will safeguard this intelligibility and also protect infant sleep. ${ }^{25}$

The permissible $\mathrm{NC}$ of an hourly $L_{\mathrm{eq}}$ of $45 \mathrm{~dB}$, A-weighted, slow response is more likely to be met in the fully operational NICU if mechanical systems and equipment are rated NC 30 or less. NC 30 translates to approximately $40 \mathrm{~dB}$ of facility noise. An additional $5 \mathrm{~dB}$ of operational noise above this background will result in an $L_{\mathrm{eq}}$ of about $45 \mathrm{~dB}$. Limiting operational noise to only $5 \mathrm{~dB}$ above the background will require conscientious human effort.

Acoustically absorptive surfaces reduce reverberation and, therefore, sound levels at a distance from the sound source. When possible, one surface of each opposing pair of walls should be covered with sound absorptive surface materials with an NRC of at least 0.65 . Where this is not possible, the upper portions of all four walls (above areas likely to be damaged by the movement of equipment) should be covered with such material. Glass should be limited to the area actually required for visualization because it is highly reflective. Whereas a variety of flooring will limit impact 
noise somewhat, specialized carpeting offers the most protection. Carpeting used in infant areas must have impermeable backing, monolithic or chemically- or heat-welded seams, and be tolerant of heavy cleaning including the use of bleach.

Fire alarms in the infant area should be restricted to flashing lights without an audible signal. The audible alarm level in other occupied areas must be adjustable. Telephones audible from the infant area should have adjustable announcing signals.

The type of water supply and faucets in infant areas should be selected so as to minimize noise, and should provide instant warm water in order to minimize time 'on'.

Noise-generating activities and equipment (e.g., vacuum tubes, refrigerators, ice machines, printers, linen and supply carts, medication and supply dispensing machines, conference areas, clerk's areas, multiple-person work stations and travel paths not essential to infant care) should be acoustically isolated from the infant area. Permanent equipment such as that listed above is included in the NC 35 limit, if it is installed within one of the areas specified in the standard.Post-construction validation of construction specifications: Noise and vibration measurement, reporting and remediation should be included in the test and balance specifications for construction of the building and for mechanical systems.

Criteria for transmission loss (TL) between adjacent spaces: with space at a premium, many incompatible adjacencies are possible in NICU designs (e.g., break area, meeting room or mechanical room sharing a wall with a nursery or sleep room). Specialized wall and floor/ceiling treatments will help to obtain the desired sound levels in these non-optimal conditions.

The criteria below are for sound TL or attenuation through horizontal barriers (e.g., walls, doors and windows) and vertical barriers (e.g., between floors). The sound transmission class (STC) rating spans speech frequencies and is relevant for separation of spaces with conversational and other occupant-generated noise. The NR rating, which covers a wider frequency span, is more relevant for mechanical noise dominated by low frequencies. The recommended criteria for TL below apply to barriers between adjacent spaces and infant areas or adult rest or sleep rooms.

\section{Adjacent spaces}

Pedestrian-only corridor

STC 45

Equipment corridor STC 55

Infant area STC 40

Reception STC 55

Meeting room with amplified sound

STC 55

Staff work area STC 55

Administrative office, conference

STC 45

Non-related area STC 50
Mechanical area NR 60-65

Electrical area NR 50-55

(adapted from Evans JB, Philbin MK. Facility and operations planning for quiet hospital nurseries. J Perinatol 2000; 20 (8): S105-12. Revised and reprinted with permission of Jack Evans, PE, The Journal of Perinatology, and Nature Publishing Company).

Sound transmission from the exterior of the building should meet the NC 30 criteria inside all spaces identified in the standard. Acoustical engineering: It is advisable to enlist the services of an acoustical engineer from the onset of the project through postconstruction validation. This specialty service is usually not covered by architectural fees and can assist in program and design development, design of mechanical systems, specification of equipment and building construction, and test and balance validation.

\section{Standard 24: safety/infant security}

The NICU shall be designed as part of an overall security program to protect the physical safety of infants, families and staff in the NICU. The NICU shall be designed to minimize the risk of infant abduction.

Interpretation. Because facility design significantly affects security, it should be a priority in the planning for renovation of an existing unit or a new unit. Care should be taken to limit the number of exits and entrances to the unit.

Control station(s) should be located within close proximity and direct visibility of the entrance to the infant-care area. The control point should be situated so that all visitors must walk past the station to enter the unit. The design should provide for maximum visibility of the nursery from the workroom or charting area. However, security considerations should not adversely affect the quality of spaces for families in the NICU. The need for security should be balanced with the needs for comfort and privacy of families and their infants.

Technological devices can be utilized in flexible and innovative manners within the design of the multiple-bed or single-infant room NICU schematic. Such technology, when utilized in conjunction with the thoughtful planning of the traffic patterns to/from and within the NICU space, support areas and family space, can facilitate a safe, yet open family friendly area.

\section{Standard 25: access to nature and other positive distractions}

When possible, views of nature shall be provided in at least one space that is accessible to all families and one space that is accessible to all staff. Other forms of positive distraction shall be provided for families in infant and family spaces, and for staff in staff spaces.

Interpretation. Culturally appropriate positive distractions provide important psychological benefits to staff and families in the 
NICU. Looking out of a window, viewing psychologically supportive art or taking a stroll in a garden may help to reduce stress or increase productivity. ${ }^{26}$ When possible, windows should have views of nature environments. These environments might consist of trees, plants, human and animal activity, gardens and landscapes. In urban settings, appropriate nature elements might include planters or water features. When such views are not possible, artwork with nature images or other nature simulations (e.g., video and artificial representations) should be provided throughout the unit. Family and staff lounge spaces are ideal locations for views of nature and other positive distractions.

Provision should be made for direct access to nature and other positive distractions within the hospital complex. These nature environments may consist of outdoor spaces such as gardens or walking paths or indoor spaces such as greenhouses and atria. Amenities within the nature environment might include water features, plant and animal life and solitary and group seating. Other positive distractions might include fitness centers and access to music.

\section{Glossary}

Ambient lighting. The continuous 'background' illumination for a specified area.

Ambient temperature. Thermal measurement of the generalized space around the neonate. Usually refers to room temperature.

Backsplash. A vertical, protective surface located behind a sink or counter.

Biobazardous. Refers to human tissue, cells, body fluids or culture materials that may contain infectious or other hazardous materials.

Brominated flame retardants. Bromide compounds that stop or diminish fire. Brominated flame retardants (BRFs) such as polybrominated diphenyl ethers are used in many products including furniture, textiles and electronic equipment to reduce the risk of fire. When heated, BRFs produce dioxins and furans (VOCs). BRFS are PBTs and suspected endocrine disruptors.

Cabinetry. Box-like furniture constructed for storage; could consist of drawers, counters or shelves.

Casework. The components that make up a cabinet.

Clear floor space. The space available for functional use that excludes other defined spaces (e.g., plumbing fixtures, anterooms, vestibules, toilet rooms, closets, lockers, wardrobes, fixed-based cabinets and wall-hung counters).

Color-rendering index ${ }^{27}$. A measure of the degree of color shift that objects undergo when illuminated by a lamp, compared with those same objects when illuminated by a reference source of comparable correlated color temperature. A CRI of 100 represents the maximum value. A lower CRI value indicates that some colors may appear unnatural when illuminated by the lamp. Incandescent lamps have a CRI above 95. The cool white fluorescent lamp has a CRI of 62; fluorescent lamps containing rare-earth phosphors are available with CRI values of 80 and above.

Cubicle. Space enclosed on multiple sides with full height or partial partitions with at least one opening without a door.

External windows. Windows located on the exterior skin of a building, looking outside the building or into courtyards.

Full-spectrum color index. A mathematical transformation of full-spectrum index into a zero to 100 scale, where the resulting values are directly comparable to CRI. An equal energy spectrum is defined as having an FSCI value of 100, a 'standard warm white' fluorescent lamp has an FSCI value of 50 and a monochromatic light source (e.g., low pressure sodium) has an FSCI value of 0 .

Gamut area. A measure of color rendering based upon volume in color space. It is the range of colors achievable on a given color reproduction medium (or present in an image on that medium) under a given set of viewing conditions.

Hands-free washing station. An area that provides a freestanding sink, meets all handwashing station requirements described in Standard 7, such as space for cleaning agents and drying capability, and in addition, is operable without the use of hands.

Infant bed. Furniture or equipment used to hold an infant.

Infant room. Contains the infant space.

Infant space. The area surrounding the infant bed and containing all support equipment and furniture.

Luminaire. A complete lighting unit consisting of a lamp or lamps and the parts designed to distribute the light, to position and protect the lamp(s), and to connect the lamp(s) to the power supply. (Also referred to as fixture.) 
Non-public service corridors. Designated traffic pathways that are restricted to staff use for staff access and patient or material transport.

Parent-infant rooms. Separate rooms in or adjacent to the NICU designed for parents to room-in with their infants during some portion of the NICU stay. These rooms include infant-care space, parent-sleeping space and facilities as described in Standard 10.

Perfluorochemicals. Perfluorochemicals (PFCs) are a family of man-made chemicals used to make products that resist heat, oil, stains, grease and water. Common uses include nonstick cookware, stain-resistant carpets and fabrics, as components of fire-fighting foam, and other industrial applications. Two chemicals in the PFC group are perfluorooctane sulfonate (PFOS; $\mathrm{C}_{8} \mathrm{~F}_{17} \mathrm{SO}_{3}$ ) and perfluorooctanoic acid (PFOA; $\mathrm{C}_{8} \mathrm{~F}_{15} \mathrm{O}_{2} \mathrm{H}$ ). The chemical structures of PFOS and PFOA make them extremely resistant to breakdown in the environment and they are considered to be PBTs and VOCs.

Persistent bioaccumulative toxins. PBTs are substances that transfer easily among air, water and land, and are stored in fatty tissue. As a consequence, they accumulate or magnify as you go up the food chain, and, thus, also span generations. Effects to human health range from eye, nose and throat irritation to organ and nervous system damage to cancer.

Pbthalate plasticizers. Phthalates currently are not listed as PBTs because there is some evidence that fish and mammals can break these down within $24 \mathrm{~h}$ of entry; however, phthalates are often VOCs and are pervasive in our environments. Phthalates are a family of chemicals used to soften plastics such as children's toys, adhesives and floor and wall covering. In healthcare, DEHP (di(2ethylhexyl) phthalate) is most often used to soften PVC medical devices including IV bags and tubing, catheters and enteral nutrition feeding bags. Phthalates are also used as fixatives in perfumes, as time-release coatings on medications, and in nail polish, to make them more flexible. AKA 'plasticizers,' they may be absorbed through the skin, inhaled or ingested. They are associated with reproductive and developmental harm, suppression of the immune system and damage to organs and the nervous system.

\section{Polychlorinated biphenyls. Polychlorinated biphenyls (PCBs)}

are mixtures of organic chemicals that are non-flammable, chemically stable and have high-insulating qualities, making them ideal in industrial and commercial applications including paints, plastics and rubber products. PCBs are considered to be PBT substances that build up in the food chain and accumulate to levels that are harmful to environmental health and carcinogenic to humans. PCBs also can be VOCs.
Positive distractions. Sensory experiences which enable an individual to focus on psychologically supportive and compelling stimuli. These stimuli are intended to divert attention from negative experiences. Positive distractions should be culturally- and age-appropriate and could range from nature and art to video games and music.

Room. Space enclosed with full-height partitions or walls equipped with a door.

Single-family rooms. Rooms within the NICU analogous to private patient rooms elsewhere in the hospital that are designed to provide for the care of one or more infants from a single family. These rooms have the usual provisions for infant care as well as space for family members to stay at the bedside or in the room for extended periods of time. A sleeping area for family members is often provided within these rooms, but may also be situated immediately adjacent to them, or elsewhere in the NICU or hospital.

Volatile organic compounds. VOCs are the primary source of indoor air pollution and are measured as organic gases. VOCs such as formaldehyde and urethane are released from products during use and are often found in pressed wood products and household products including paint and wood preservatives. Importantly, the EPA reports that levels of VOCs average 2 to 5 times higher in indoor environments than outdoor. Health effects are directly related to the amount of exposure, but range from allergies to nervous system disorders to cancer.

Acoustic Terms (Disclaimer: The following terms are defined in conceptually although not technically accurate language. Technically precise definitions can be found in official documents and professional textbooks.)

Allowable sound level criteria, NC and room criteria. Sound levels can be measured over the entire spectrum of audible frequencies. For some technical purposes (e.g., spaces in which verbal communication is important), the spectrum can be divided into smaller frequency spans, such as octaves or specific narrow bandwidths. Background noise within a room is often measured in octave bands for comparison with a family of smooth, balanced curves, called NC or room criteria (RC). This criteria system is used for design and validation of building spaces because it is more descriptive than a single number such as $\mathrm{dB}$ or $\mathrm{dBA}$, which does not carry enough information to distinguish between a pure tone, a balanced spectrum or sound dominated by lower or higher frequencies.

Background or facility noise. Background noise refers to the continuous ambient sound in a space owing to the mechanical and electrical systems of the facility or building itself. Background 
noise is produced by sources outside the building and by the building's own HVAC systems, vacuum tube systems, elevators, plumbing, automatic doors, etc. Because occupant-generated noise will add to the 'noise floor' or background noise of the building, allowable background level criteria are set low enough to prevent annoyance, reduced speech intelligibility, sleep disturbance, or other disturbance after the building is occupied.

Facility us operational noise. Exterior sources (e.g., street traffic and outdoor building mechanical equipment) and interior sources (e.g., air conditioning and exhaust systems) generate facility noise. It exists in the empty building as it is constructed. The people and equipment that occupy the building generate operational noise.

Operational noise. Operational noise is generated by people and equipment that occupy the building and are separable from the building. A general rule of thumb states that occupants and their equipment will add about $10 \mathrm{dBA}$ to background noise. However, this generalization does not apply to all room uses. For example, two or three people in an office environment with 45 to $55 \mathrm{dBA}$ background might add about $10 \mathrm{dBA}$, but the same group in a quiet conference room with a 35 to $45 \mathrm{dBA}$ background might add $20 \mathrm{dBA}$. A large group of people might add $40 \mathrm{dBA}$. In intensive care units with hard surfaces, close spacing of patient beds and large amounts of staff and equipment, the occupied room noise may be $20 \mathrm{dBA}$ or more above background with brief excursions well above that.

Occupant-produced noise. Occupant noise is not under the control of architects and engineers but can be incorporated as a design parameter through the use of a matching architectural requirement (e.g., wall and ceiling absorption criteria). Control of occupant-produced noise lies primarily in the realm of quality assurance programs and hospital management.

Reflective and absorptive surfaces: NRC. Within any closed space, sound levels are affected by reflections of sound waves from surfaces. When the surfaces are predominantly hard, sound pressure builds up in the space, increasing the original level with reverberation. Conversely, when the surfaces are soft or acoustically absorptive, reflected energy is reduced and sound pressure does not build up. Acoustically absorptive surface materials are rated by an $\mathrm{NRC}$, which is an average of absorption coefficients in the middle range of the audible spectrum of sound frequencies. Although an oversimplification, the NRC rating of a material can be thought of as the percentage of sound energy absorbed. If the NRC of a wall panel, for example, is 0.65 , about $65 \%$ of the sound energy of a source is absorbed and about $35 \%$ reflected back into the room.

Vibration. Vibration is perceptible to humans at a certain magnitude or level and can cause discomfort or annoyance. Larger magnitudes of vibration can cause rattling of lightweight building elements, superficial cracking in partitions or even structural damage. Very small magnitudes of vibration not perceptible to humans can disturb high magnification optical microscopes or very sensitive electronic equipment. Sources of vibration common in hospitals are helicopter flyovers and landings/take-offs, magnetic resonance imagers, sound systems and heavy trucks. Buildings can be constructed to prevent the propagation of vibration through the building.

\section{References}

1 Committee on Perinatal Health. Toward Improving the Outcome of Pregnancy. Recommendations for the Regional Development of Maternal and Perinatal Services. The National Foundation - March of Dimes: White Plains, NY, 1976.

2 Guidelines for Perinatal Care. 6th edn American Academy of Pediatrics/ American College of Obstetricians and Gynecologists: Elk Grove Village, IL/Washington DC, 2002.

3 Guidelines for Design and Construction of Hospital and Health Care Facilities. The American Institute of Architects Academy of Architecture for Health: Washington, DC, 2006.

4 Committee on Perinatal Health. Toward Improving the Outcome of Pregnancy. The 90's and Beyond. The National Foundation - March of Dimes: White Plains, NY, 1993.

5 White RD (ed).. The sensory environment of the NICU: scientific and design-related aspects. Clin Perinatol 2004; 31(2): 199-388.

6 NFPA 99 Standard for Health Care Facilities. National Fire Protection Association: Quincy, MA, 2005.

7 Green Guide for Health Care. (available for download at www.gghc.org). 2006

8 Robbins, Sandra T, Beker, Leila T, American Dietetic Association. Pediatric Nutrition Practice Group. Infant Feedings: Preparation of Formula and Breastmilk in Health Care Facilities. American Dietetic Association: Chicago, 2004.

9 Rea MS (ed) IESNA Lighting Handbook, 9th edn. Illuminating Engineering Society of North America: New York, 2000

10 Rea M, Deng L, Wolsey R. NLPIP Lighting Answers: Light Sources and Color. Vol 8, Issue 1. Lighting Research Center: Troy, New York, 2004.

11 Lighting for Healthcare Facilities, RP2. Illuminating Engineering Society of North America: New York, 1995.

12 Rivkees SA. Emergence and influences of circadian rhythmicity in infants. Clin Perinatol 2004; 31(2): 217-228.

13 Glickman G, Byrne B, Pineda C, Hauck WW, Brainard GC. Light therapy for seasonal affective disorder with blue narrow-band light-emitting diodes (LEDs). Biol Psychiatry 2006; 59(6): 502-507.

14 Figueiro MG, Eggleston G, Rea MS. Effects of light exposure on behavior of Alzheimer's patients - a pilot study. Light and Human Health: EPRI/LRO 5th International Lighting Research Symposium. The Lighting Research Office of the Electric Power Research Institute: Palo Alto, CA, 2002, pp 151-156.

15 Ulrich R. Effects of interior design on wellness: theory and recent scientific research. J Health Care Inter Des 1991; 3: 97-109.

16 General Paint. Technical Data Manualhttp://www.generalpaint.com/tdm/ docs/Permit_Access/main.cfm(accessed 4th November 2006) 
17 Obein G, Knoblauch K, Viénot F. Difference scaling of gloss: nonlinearity, binocularity, and constancy. J Vis 2004; 4(9): 711-720.

18 Nadal ME, Thompson EA. New primary standard for specular gloss measurement. J Coatings Technol 2000; 72(911): 61-66.

19 Anderson RL, Mackel DC, Stoler BS, Mallison GF. Carpeting in hospitals: an epidemiological evaluation. J Clin Microbiol 1982; 15(3): 408-415.

20 White R. New Unit Focus: Memorial Hospital of South Bend, in Perspectives in NICU Planning, Report of the Fourth Annual Ross Planning Associates Symposium. Ross Laboratories: Columbus, OH, 1988.

21 US Environmental Protection Agency. Envirofacts master chemical integrator (EMCI) http://www.epa.gov/enviro/html/emci/chemref/(accessed 5th August 2006). 2006

22 Standard Terminology Relating to Environmental Acoustics (ASTM C-634). American Society for Testing and Materials: West Conshohocken, PA, 2001.
23 ASHRAE Handbook: Heating, Ventilating, and Air-Conditioning Applications: Inch-Pound Edition. American Society of Heating, Refrigerating and Air Conditioning Engineers: Atlanta, 2003.

24 Gray L, Philbin MK. Effects of the neonatal intensive care unit on auditory attention and distraction. Clin Perinatol 2004; 31: $243-260$

25 Philbin MK, Robertson AF, Hall III JW. Recommended permissible noise criteria for newly constructed or renovated hospital nurseries. J Perinatol 1999; 19(8, Part 1): 559-563

26 Parsons R, Tassinary LG, Ulrich RS, Hebl MR, Grossman-Alexander M. The view from the road: implications for stress recovery and immunization. J Environ Psychol 1998; 18: 113-140.

27 Lighting Research Center. http://www.lrc.rpi.edu/programs/NLPIP/ glossary.asp (accessed 15th April 2006). 